\title{
The Effect of Electroacoustic Music in Enhancing Interpersonal Relationships in School Community An Empirical Research for Secondary Education
}

\author{
VASSILEIA BOURA \\ Patriarchal University Ecclesiastical Academy of Crete \\ Herakleion, Crete, Greece
}

\begin{abstract}
Electroacoustic music, as the contemporary art of sounds originating from the human environment, is selected to play a unifying role of interdisciplinary study areas in school, but also be the vehicle for the school community to form links with the wider society for enhancing students' learning, emotional skills and carrier orientation. Electroacoustic music learning methods are empiricaly proved to play an important role in students' education and in future citizens' attitude and ethics. This paper is based on empirical practices and statistically analysed results. Previous studies, worldwide, have shown a positive relationship between music and academic achievement. This study explores the possible reasons why electroacoustic music positively affects interpersonal relationships in school environment. Educators and curriculum developers may want to include electroacoustic music in their instructional units, on an international level. Bioscientists and psychologists may extend this empirical research to scientific. Since 2012 different empirical educational programmes in Greek European and public schools under the auspices of the Hellenic Ministry of Education and Religious Affairs, have aimed to enhance learning and intra-school interpersonal relationships in Secondary Education. The programmes reffered to in this paper discribe the results of electroacoustic music effect on interpersonal relationships in the school environment.
\end{abstract}

Keywords:- Electroacoustic Music; Interpersonal Relationships; Secondary Education;

\section{INTRODUCTION}

As an electroacoustic composer and at the same time a music educator in undergraduate education and in secondary schools of Greece for over 20 years, I have applied an interdisciplinary role to electroacoustic music in teaching and learning. I have experienced the positive effects of electroacoustic teaching methods and activities, on students character shaping, interpersonal relationships and career orientation. I have observed the great effects of electroacoustic experiences on intra-school and extra-school society connections and links.
Secondary education curriculum in Greece, among other goals is challenged to promote emotional education, to suppress violence, racism and diversity (social, cultural, economical, educational), to promote a positive atmosphere of cooperation between students, parents, school administration, educators and society, to facilitate student inclusion and adaptation by promoting the well-being. Interpersonal relationship skills, within the school environment and with society, are critical for enhancing learning and well-being, not only for students, but also for the wider school community.

In modern schools, music affects a student's character and values, contributes to conflict solving, helps adjustment and motivation, enhances communication, expression and collaboration, reduces violence by controlling racism and diversity, increases mental functions by improving psychological and physical health (Lozanov, 1960 and Brewer, 1995). Could electroacoustic music also affect students in that way?

In the context of New School (2011), a revised curriculum of school and social life for Greek schools, empirical educational programmes have been approved for public and European schools in Greece, by the Hellenic Ministry of Education and Religion Affairs. Through the programmes, an effort to reach out to students and the wider school community was made. The aim was to improve learning and social skills in the intra-school community. In the programmes referred to in this paper electroacoustic projects and multicultural activities in the context of an integrated education were conducted. Collaboration, between educators, students and the school community were planned. Interpersonal relationships expected to be built upon music experience. The effect of electroacoustic music in cognitive, physical, emotional and social skills was observed and analysed. The electroacoustic programmes took place from 2013 to 2016.

The aim was to investigate the effect of electroacoustic music practice on improving students' interpersonal relationships and social skills, improving wellness and prosperity as future citizens. Furthermore, electroacoustic music was introduced to the students and the school society, as a contemporary scientific art form, that would help them reinforce their expression and communication skills. 


\section{MATERIALS AND METHODS}

Electroacoustic music has only recently been introduced, as a separate chapter in Greek music books. Consequently, the need arose for music educators to find alternative and innovative ways to motivate students creativity and expression through electroacoustic music. Many composers and theoretics on the field, such as Trevor Wishart (a,b), Barry Truax (1992), Dennis Smalley (1992), Vassileia Boura (2007) and many others, have expressed theories and methods for electroacoustic music to become more perceivable by the audience and eventually better appreciated. Electroacoustic music in Greece is considered a scientific, extraordinary and abstract art form, studied and composed by a limited number of expertised musicians. It is listened to by an even lesser number of listeners. Thus, in order for students to be introduced to electroacoustic music and at the same time to learn how to perceive and appreciate it, eight empirical educational programmes were conducted by me in collaboration with a team of educators in other fields of studies, in a public school in the city of Heraklion in Crete. The 8th public Gymnasium. The programmes were conducted in the context of New School curriculum (2011) introduced by the Ministry of Education and Religion Affairs of Greece. The goal was improve interpersonal relationships between all members of the school community, seeking their well-being and prosperity. The total number of students participated in the following educational programmes was 676, aged between 12 and 16 years old, from all three secondary education grades. Electroacoustic music was integrated in class, in different subjects, primarily as a soundtrack music, then, as a creative medium to activate information (mental, physical and emotional) and to express and reflect students' emotions and finally, as an interdisciplinary medium for increasing knowledge, learning motivation and social skills to the students.

All the students who participated in the educational programmes attended the particular school units, were between 12 and 16 years old and came from different cultures, social or economic statuses, had different nationalities, learning difficulties, special needs, or cognitive levels. All students were included without discrimination in the educational programmes.

The programmes were running simultaneously for the three different grades of the Secondaty education school, integrated in each class curriculum, during and after school hours. Each programme was running in addition to the other and in progress and continuation of the previous one. The teaching methods and activities were set at the first programme in 2013 and they were applied and improved to the following ones. Students were initially introduced to electroacoustic music theories and historical background for the first two months of the programme and then they were gradually introduced to music technology practices and electroacoustic composition techniques, coming eventually to the point where they could compose their own music by the end of the programme. The integration of electroacoustic music to different classes took place in all programmes, regardless of their running time. The participation was compulsory for all students. My task was to organise and supervise all the programmes. The educational programmes' titles, as they were approved by the Hellenic Ministry of Education and Religious Affairs, in the context of Education and Lifelong Learning, New school - Innovative Education programme are the following.

2013-2016: Cultural-Educational programme title: "Electroacoustic music as a medium for identifying myself and communicating with my classmates". Empirical activities within Civilization and Art curriculum for the first year of Secondary Education. Directorate of Secondary Education, 8th Gymnasium, Heraklion, Crete, Greece.

> 2014-2015: Cultural-Educational programme title: "Contemporary Music and Dances from all over world" Empirical activities within Civilization and Art curriculum for the second year of Secondary Education. Directorate of Secondary Education, 8th Gymnasium, Heraklion, Crete, Greece.

$>$ 2013-2015: Commenius programme title: "Medieval era evolves today. Multilateral Project" (collaboration between countries: Roumania, Poland, Greece, Lithuania and Turkey) Electroacoustic music soundtrack and composition. 8th Gymnasium, Herakleion, Crete, Greece.

The methods applied and the activities performed in these electroacoustic music programmes, were inspired by previous scientific researches on the integration of music in general, in the classes, such as John Hopkin's Study in integrating music in the classroom (Brewer, 1995), the Active Learning Experiences using music in the classroom (Lazarov, 1960), the "Mozart Effect" (Campbell, 2001) and the research on How arts integration supports student learning (DeMoss, K. \& Morris, T., 2002). Counter to previous researches, electroacoustic music was used, not any other orchestral, or contemporary musical style.

The extra particular methods and practices we used to integrate electroacoustic music in the school community and to investigate enhancment in personal relationships are the following.

Background electroacoustic music during breaks. Small, 10 minute, presentations and music performances in different break times during the week. Students were presenting their work in a radio style programme, while electroacoustic music groups were performing live in the school yard.

20 minute lunch time break concerts. Students performed their electroacoustic compositions or short films and animations with electroacoustic soundtracks, in the music technology room or in the school's concert hall.

Small lectures on the multidisciplinary topics of electroacoustic music performed by students, with the music educator's supervision. Everyone in the school community was invited to attend. 
School celebrations, events and concerts in collaboration with the local educational and cultural bodies. Students' electroacoustic music compositions and remixes were were performed.

Optional electroacoustic music listening with headphones during studying in the school library.

Experimental use of sound dynamics, timbre and pitche changes that were playing for 2 minutes during school breaks. Silence, low density musical extracts and very loud sounds, one following the other, were playing during break times. Students familiarise themselves with the notion of music and sound dynamics. Different sound sources were playing through the loudspeakers in the school yard during break time, as well as different pitches of the same sound source. The above experimental sound material was produced by students during the music class in the music technology room of the school.

Educational trips to attend local orchestras/band rehearsals and concerts, professional music studios, university departments of music and music technology and acoustics. Students were getting acquainted with professionals in the electroacoustic music and the music technology field. Vocational information and guidance was offered to students interested in studying music.

Vice versa, different bands and orchestras were invited to visit school premises, to give a concert and discuss with students, educators and parents/guardians.

Educational trips to radio and TV stations. Students were organising radio and TV shows on topics related to electroacoustic music, for one hour per week. Broadcasting to wider audiences, than only to the school community, was an attempt to communicate with wider numbers of students and people and familiarise them with electroacoustic music. Radio and TV stations offered their air time to students' broadcastings, for several different reasons each (charity, advertising, publicity and so on), for free.

Students produced radio and TV advertising spots, in the music technology room, for promoting school concerts and events. They were broadcasted for free from local radio and tv stations in the context of the school society collaboration of the educational programmes.

Final year multicultural concerts. The total of the produced electroacoustic work of the students was presented and performed in a large festival activity, that took place in an open air theater of the town. Electroacoustic remixes of different styles of music worldwide, short films, animation films and multicultural electroacoustic dance remixes with folkloric costumes were performed in an open air, open to the public concert. Local bodies and authorities, as well as, local school administrations, parents, guardians and students were invited to attend. A large scale collaboration between the educators of the school and the society in organising the event, took place. Adults and adolescents were working together in producing audio and visual art events that introduced integrated education and depicted intercultural communication elements within the local society.

Electroacoustic music was integrated in school class (Boura, 2020) to increase social skills to the students. Such as: Playing electroacoustic music as background music for class entries, exits and breaks. Use electroacoustic music listening for relaxation, or stimulation, or even as an offence behaviour penalty inside, or outside the class, or during detention. Use of electroacoustic music throughout the class curriculum increasing music intelligence. Observation of the effect of electroacoustic music to students' mood swings in music classes. Students are requested to realise the effect of electroacoustic music to their emotions, behaviour and state of mind and expand their musical memory exercising selfcontrol and self-knowledge. Observation of the effect of background electroacoustic music to students' mood swings in different curriculum classes.

A qualitative data collection and analyses was used. Information about the students' attitude and behaviour was recorded by students' interviews, tests, semester assessments and penalty recording. We interviewed students before and after class to gather information about motivation and interest changes in a particular topic. Students were also asked to answer questionnaires in order for educators to analyse their responses and assess the effect of electroacoustic music on improving social skills in the electroacoustic music integrated classes, compared to traditional non electroacoustic ones from the past. Class attention, attitude and atmosphere was also observed to understand the interpersonal relationships achieved between educators and students, and between students themselves, during electroacoustic music integrated classes. Programmes' interviews and evaluation paper results were compared with previous school evaluation papers on students' learning efficiency and school life, retrieved from the school's archive. School evaluations are conducted every two years. The results of the integration of electroacoustic music in the classroom, which are presented in this paper, have been measured based on the deviance between the preprogrammes' and the post-programmes' evaluation papers.

In addition several methods for monitoring students' social skill improvement were used. Such as: discipline/detention records for each student, school psychologist semester reports on school violence, questionnaires that were provided to school director, students, educators and parents/guardians to be answered, concerning the effect of the electroacoustic music to the overall student performance during the course of the educational programmes.

Additional information, on the effect of electroacoustic music integration in school subjects, were drawn from the participation level of students, educators, parents/guardians and the wider society in all the electroacoustic events, which was measured by ticket selling, newspaper reports, and municipal and private voluntary funding on extra supporting this effort to integrate electroacoustic music to the school society. 
In order to incorporate electroacoustic music into the different classes and the school community, CD players and computer devices were used. Computer sciences and Music Technology rooms were available to be used by all participated students and educators. Web-based music programmes and digital audio workstations (DAWs) were also available to the students. In addition, several musical instruments were available to the students for practice and recording. The electroacoustic compositions used are listed in the appendix of this paper.

Extra precaution measures were taken by the school administration for afterschool programme sessions and activities, and additional written approvals were requested by the parents/guardians.

\section{RESULTS}

The expected results concerned the effect of electroacoustic music to students' socialisation, personality and life attitude.

After considering multiple forms of evidence (interviews, questionnaire, tests and assessment/evaluation papers) and statistically analysing them, the programme supervisor together with the educators involved in the educational programmes found that certain approaches to the integration of electroacoustic music in school life was associated with positive students' personal interrelations outcomes (Boura, 2020).

Additional results, on the effectiveness of electroacoustic music teaching in school, were drawn from the participation level of educators, parents/guardians and society in all the electroacoustic events. The subject of electroacoustic music was considered innovative, interesting and professionally accessible for students. Eventually, parents/guardians gladly accepted the invitation to participate in events that made their children happy, creative and socially active, supporting them. The enthusiasm of students was well received by local bodies and authorities, which strongly supported every student effort for public presentation and performance. The city community responded positively as well. After the completion of the educational music programmes there were still students and school community people, who, although they had learned to appreciate the electroacoustic musical form, their aesthetical opinion towards electroacoustic music remained biased.

Integrating electroacoustic music in classes, not only affected students' learning skills, but also, their emotional state. Healthy multidisciplinary learning affected students' physical, emotional and social skills, physical and emotional readiness and expression, social dexterity and interpersonal relationships, wellbeing and prosperity.

Electroacoustic music was taught extensively in music class, both in theory and in practice, improving students' musical knowledge in a personal and real-experience level. Working individually and collectively students not only improved their listening and compositional skills, but also understood and appreciated contemporary styles of music.

Procedures of emotional production, processing, recognition, reflection and recollection, by listening to electroacoustic music improved students' self-knowledge. Conscious and rational emotion management techniques, such as conscious management and control of breathing and conscious imposition of rationalised and rational thinking on specific emotions and reactions of the body breathing control and yoga exercises, were approached by students under the supervision of school's psychologist and physical educator. Students' interviews results showed that 35\% of the students could relax and reduce their anxiety and stress by listening to electroacoustic music, while $60 \%$ of the students were stimulated and activated. $5 \%$ of the students claimed to be indifferent to the effects of electroacoustic music on their emotional state.

Working on philosophical and sociological issues, related to electroacoustic music, students were able to form a framework of values and principles that govern the arts and human culture, shaping their own aesthetics in producing art forms, and especially electroacoustic music. Students' oral and written assignment evaluation, by the school's music, philosophy and psychology educators, at the beginning and at the end of the educational programmes, identified a change in the way students approach the value and evaluation of electroacoustic music, as an art form. 87\% of the students reevaluated their positions on what they considered as music, 54\% of the students formed a revised approach to what is considered as beautiful and nice in music, while $34 \%$ of the students declared with enthusiasm that their musical tastes had expanded considerably (figure 6 ), compared to those at the beginning of the programme (figure 5). 56\% of the students in the later case were coming from traditional closed societies and villages near Heraklion city. These students, from more traditional cultures, were the most enthusiastic and eager to learn music technology, and to immerse themselves in the aesthetics of contemporary electroacoustic music. The interviews showed that the process of learning and creating electro-acoustic music made the later students feel more integrated in modern society, being citizens of the world, instead of being isolated and stuck in tradition, imposed on them by the closed society in which they were born and raised. Nonetheless, $32 \%$ of traditional origin students, remained faithful to their tradition and values and refused to accept any change in their musical tastes and aesthetics. In addition, city origin students, already familiar with computer technology and music fans of a wide variety of contemporary styles of music, approached electroacoustic music as a natural evolution of music theory and practice, although they found difficult to accept its aesthetics. It is to be clarified that Heraklion, as the capital city of Crete, is basically a traditional community, with great cultural influences from abroad over the years, and with great scientific and technological institutions conducting modern research and absorbing hundreds of permanent, or visiting, scientists and professionals from around the world. It is a fusion of contemporary and traditional elements, which eventually affect the way that local people live and think. 


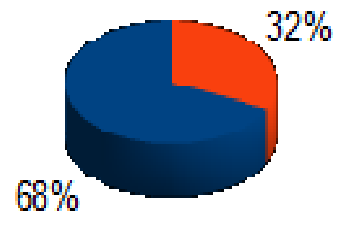

Village origin students

n City origin students

Fig 1:- Traditional musical tastes of the students at the beginning of the educational programmers.

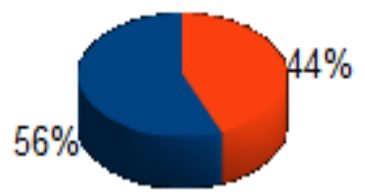

Village origin students

City origin students

Fig 2:- Musical tastes of students expanded to include electroacoustic music at the end of the educational programmers.

The interdisciplinary learning of electroacoustic music arose plenty of debates, in class and in public, on different philosophical, ethical, social and scientific issues, related to electroacoustic music, making students to practice their selfesteem, self-knowledge and self-awareness, by supporting their different arguments. $67 \%$ of the students mentioned in the interviews that although they found debates stressful at first, at the end their knowledge and opinions on several issues were improved and their confidence and self-esteem were strengthened. By practicing self-control and selfrestraint during the debates, students developed emotional and social skills. A $56 \%$ of the students admitted in the questionnaires that they practiced self-control in all the debates, waiting for their turn to come to express their opposite opinion on an issue. $64 \%$ of the students claimed that by improving their musical listening skills, through electroacoustic activities, they also improved their ability to listen carefully to their interlocutors during the debates, or to their classmates and educators during classes. $72 \%$ of the students admitted that they practiced active listening, so that their ability to understand and accept an opposite opinion improved.

Integrating electroacoustic music in science and humanities, intrigued $85 \%$ of the students, as they claimed, in searching related topics on the internet, in their spare time at home. $56 \%$ of the later students spent more than two hours daily searching on the internet for electroacoustic related information. $76 \%$ of the students claimed that they had started listening to electroacoustic music, outside school, in their everyday life, for the first time, either to concentrate $(32 \%)$, to hang out with friends $(36 \%)$, or as a background music (8\%). About $89 \%$ of the students participated in the educational programmes, entered the process of composing music for the first time. Expressing personal feelings and beliefs in the language of electroacoustic sound, gave students the opportunity to communicate and to channel any oppressed feelings and ideas through music, in a free artistic way, without censorship. All students, without exception, composed electroacoustic music pieces. $75 \%$ of the students composed more than one piece. All the students stated in the interviews that expressing themselves through electroacoustic composition was an easy, without the additional need for special musical or scientific knowledge, way.

Improving their musical intelligence, students managed to improve their emotional intelligence, as well. Incorporating electroacoustic music in the class helped students use their musical intelligence as a vehicle for carrying out multiple intelligence activities in different discipline class curriculums. That procedure allowed students to express themselves freely and creatively on how they feel about issues brought up in literature, historic, social, religious, scientific, artistic studies topics, improving eventually their personal expression. Students by improving their ability to respond to musical sound and to use it in their everyday lives (inside and outside school) affected their level of emotional intelligence. Electroacoustic music was also used by all students for personal expression in dancing, in creative writing, in drawing, in class, during breaks, and debates, in composing electroacoustic music on a poem, text or drawing, by being a creative member of an electroacoustic work team and in decision making for electroacoustic music projects. Based on students' responses to questionnaire and evaluation papers (figure 7), electroacoustic activities in class and during break and lunch times, improved their emotional skills in self-restraint (by $30 \%$ ) and self-control (by $45 \%$ ), improved their behaviour towards their classmates $(68 \%)$ and their educators $(56 \%)$. In addition, electroacoustic activities helped students increase their self-knowledge (35\%), self-esteem $(65 \%)$, self-acceptance $(40 \%)$ and self-confidence $(67 \%)$, a fact that helped them establish better collaboration and communication skills with their classmates $(75 \%)$ and their educators $(42 \%)$, reducing their anxiety and stress $(87 \%)$, and becoming able to solve problems $(46 \%)$ or set feasible goals $(35 \%) .79 \%$ of the students also reported a relieve of their mental fatigue, due to the reduction of the time they spent to store knowledge in conventional classes, as opposed to the empirical interdisciplinary learning techniques they used during the electroacoustic activities of the programmes. $75 \%$ of the students said that joy and fun were added to the class activities, during educational programmes. As a result, students' marks improved together with their participation in the class, and their productivity, as mentioned in the previous chapter. 


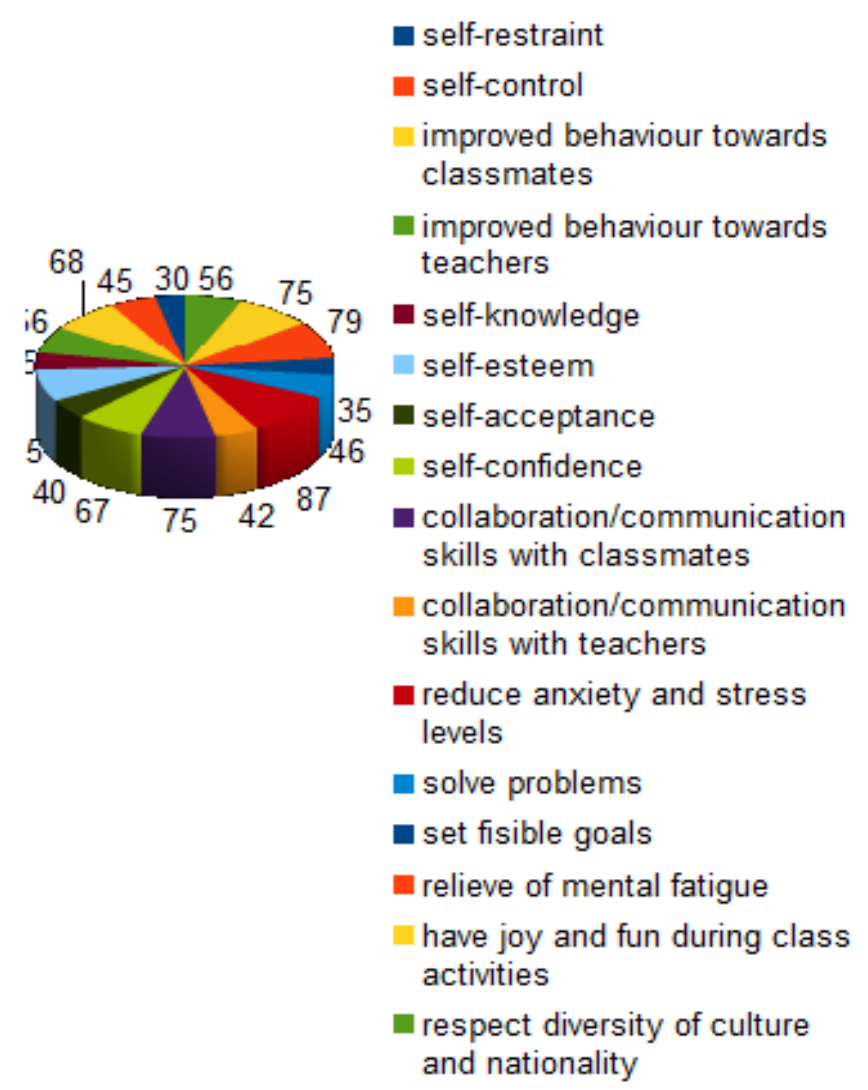

Fig 3:- Positive students' response percentages (\%) on the effect of electroacoustic integration on their emotional skills.

Furthermore, students claimed to have become fitter as they enjoyed more to participate in physical education exercises and events that allowed them to improvise in body movement and utilise technology to produce sound with their body motion. They even renamed the physical education class to "fan and fit class". $48 \%$ of the students stated in interviews that they paid more attention to their diet so that they could move more easily in the gym class and look better during the public events.

Students during the educational programmes learned to use and communicate with the same musical language, sharing multidisciplinary knowledge, exercising skills, feeling members of the same community who are working for the same goal. In the final assessment interviews, educators commented that electroacoustic music provided a positive environment for students to interact, communicate, and collaborate during the different classes, regardless of the learning methods they used. Specifically, students were conversing, laughing, exchanging ideas, cooperating. It was as if electroacoustic music broke down the walls and everyone was free to express himself and communicate, forgetting differences and diverses. $56 \%$ of the students replied positively in the class evaluation papers that, by the multicultural activities of electroacoustic music integration, they learned to understand and respect diversity of culture and nationality. Electroacoustic music projects provided a positive environment for interaction, developing communication, collaboration and team creativity, in the sense of school community and cooperation, overcoming students' intercultural and social-economic issues, integrating and adapting students with special needs and learning difficulties. Analysing the data of 1) the schools' penalty book, where all students' granted penalties are recorded, 2) the results of the students interviews, during the course of the educational programmes and 3) the reports from the supervising educators during break times in the school yard, a few very interesting outcomes were noticed. Students penalties were reduced by $65 \%$ during the course of the educational programmes. Booling events during break times were reduced substantially. Students' aggressive behaviour, in classes that joined the educational programmes, was reduced or controlled by educators more easily. Racist incidents were completely vanished by the end of the programmes. Students stated that friendships were developed between classmates that were not even speaking to each other before working together in the electroacoustic activities of the programmes. Furthermore, students commented in the final evaluation interviews that they anticipated the different multidisciplinary electroacoustic tasks, concerts and events inside and outside class, making school more fun and entertaining to them. The multidisciplinary knowledge and the skills they were building, musical or social, afforded them the ability to apply these skills and knowledge in real life situations and make meaningful contributions to society. Organising and carrying out a project, a debate, a concert, made students confront their deficiencies, practice and improve their skills, establish powerful and meaningful interpersonal relationships inside and outside school.

Students who undertook different electroacoustic projects were asked to work individually, or in groups, to cooperate and collaborate in solving differences and overcome diversities and inequalities. They were asked to take the responsibility of organising an electroacoustic event, communicating and collaborating not only with their classmates and educators, but also, with the school administration, with several local bodies, businesses, professionals, scientists, parents association and with the wider local community. They were asked to stand in confidence in front of an audience to present their work, to learn to ask for help when they needed it, to put aside their personal beliefs and prejudices for the common goal and work with empathy. At the educator's exhortations students sprang into action, supported by the school administration. Students orginised and gave successful electroacoustic concerts, built up interesting school debates and did several radio and tv shows on electroacoustic relative issues. Hundreds of people participated and watched. Post evaluation by students showed that their self-esteem, selfawareness, self-knowledge and self-confidence were greatly improved. Students were opened to the society, applying their knowledge, and the society entered school premises, exchanging knowledge and experiences with the school community in a cognitive, emotional and social communication. The local society was informed about the students' electroacoustic work and experienced the results of students' cooperation, no matter their religious, socialeconomic, or cultural background. The integration of electroacoustic music to science and humanities was introduced to the local society for the first time. Local 
authorities and bodies, as well as parents and audience, congratulated and appreciated educators and the school administration for their work and offer to the students and the society, expressing their admiration, respect and financial support for the continuation of the educational programmes. Businesses and professionals talked about business and career opportunities to students and their parents. Students claimed during the final evaluation interviews that their self-confidence was improved and they gained back the respect of their parents and friends substantially, because of the wide appreciation and recognition of their work. They also claimed to be more certain and secure about their future. The school community was introduced to local professionals and businesses in the field of electroacoustic music, but also to scientists and artists in fields related to electroacoustic music. They visited school and gave lectures on their individual fields of knowledge and students visited their work or research premises during field/educational trips. School extroversion created social ties, as well as, links between school community and institutions. During the five year educational programmes school and local community became an interdependent system of knowledge and experience flow, shaping trends, characters, creative labor opportunities, active educated citizens, with a wide knowledge and experience, with understanding and respect for diversity.

The programmes had positive effects not only on the students but also on the participating educators. During the educators' final interviews, feelings of gratitude and satisfaction were expressed by them. They stated that, collaborating with each other in helping and supporting students, they felt that they became a row model for them. Their actions and behaviour affected students behaviour and productivity. They overcame the burn out at their work and avoided feelings of depreciation by their students and their colleagues, even from the school administration. Their communication with colleagues and school administration improved. They regained respect for themselves and for their colleagues. They claimed to be happy at work every day, offering their knowledge and services for shaping characters and attitudes for a common goal and eventually for the greater good of the society. They claimed that they remembered their role as educators and the joy that accompanies it.

The management of the school, seeing the response of the society, but also observing the change in the behavior and the increase in creativity of the students became more humane, compassionate and supportive towards students and educators. The office door of the school director was open for everyone to enter, at any time. The behavioural penalties decreased by $65 \%$ according to the penalty book records. Educators and school administration were mostly talking through the conflicts rather than punishing unacceptable behaviours. As mentioned above, that is also due to the students self-restraint and self-control attitudes that were also increased. The school directors, in the final evaluation interview, claimed to be proud of the work educators and students acomplished and confident that these programmes would continue to run, be appreciated and supported by the local community. The school directors became in favor of a more emotional management of the school, based on respect and communication, which enabled students to express themselves freely and creatively. They claimed to have observed the effect of coming into contact with society and to communicate and exchange ideas and feelings with it, on helping school to reform society but also society to reform school.

One of the most effective contributions of educators and school administration was to help students get positive or negative feedback of their work in a constructive way. Strengthening students' self-esteem and self-confidence by collaborating, sharing ideas, feelings and experiences, troubleshooting together, accepting criticism and resolving crises together, school educators and administration actions had echoes and reverberations that contributed to students lives inside and outside school.

As electroacoustic music was not popular among local society, students apart from their own dissenting opinions on electroacoustic aesthetics, had to deal with the audience's as well. Students practised in not discouraging themselves by the audience's taste in music. They were encouraged to present each piece of electroacoustic music at the concerts with an explanatory program note. They practiced in accepting musical aesthetics. They were encouraged to discuss the feedback and reflection of their work. Students were introduced to communication with respectful controversy and contradiction about their compositions by the several debate practices during the educational programmes, along with the different ways of communication (verbal and non-verbal communication) as taught by the psychology educator.

A great inconvenience was to deal with the extensive bureaucracy for obtaining permission, either from the school administration, or from the Directorate of Secondary Education, or from the local authorities, to move students out of school, or to invite people in school, or even more, to organise out-of-school events. The paperwork and the time taken was enormous. Nevertheless, the positive attitude of many civil servants hastened the proceedings substantially.

Furthermore, educators had to deal with students who were neglected or experiencing violent situations at home. Those students often had learning difficulties and expressed the wish to give up their school obligations, or even drop out of school. Different types of music, depending on their culture and preferences, helped those students consciously to impose themselves on their brain. A series of musical compositions (electroacoustic or not) related to relax and stimulation emotions, together with the support and counselling of school psychologist, on a daily basis, helped them overcome their difficulties to be able to participate actively in the programmes' electroacoustic activities.

Several obstacles have emerged mainly due to some peoples' prejudice towards anything innovative, out of the ordinary or traditional way of thinking, concerning school education methods, from both parents and school administration. Additional inconvenience was caused by the 
noise during student collaboration and composition time, due to the lack of soundproofing of school walls, by ensuring technical support for music technology room, with the kind sponsorship of parents and individuals, by the skepticism of some parents and collegues claiming that the programmes were taking too much of students time, that we had to overcome by frequently organising parent information days, where educators and school administration were also present.

\section{DISCUSSION}

In the educational programmes of this paper, apart from providing schools' adolescents and adults a relaxing and imaginative way to cope with everyday life, electroacoustic music initiated an educational and therapeutic role for the school community in enhancing learning and interpersonal relationships, which ultimately lead to success.

Music, in ancient times, had the primary role of structuring human education and human personality. The finest of all arts, according to Plato, aimed not only at human entertainment but also at mental stimulation, or relaxation. On the contrary, in modern Greek schools, the role of music in structuring educational systems and human personalities has been degraded. Musci is rather an additional, optional knowledge for students' wider education, a fact that has been exacerbated by the economic crisis of the last decade.

Music educators in Greek public schools strangle in the class between noise, or ignorance and depreciation by their students and colleges. Yet, they are expected to organise and supervise every cultural event, or national celebration, inside, or outside the school, to culturally refine students and the school community, to play a mediator's role between school and society.

Music has become a quite extended field of knowledge for a student to cover in Greek secondary schools. The art of sound evolved at the beginning of the 20th century and ever since it has acquired different forms and names, such as art of noises, acousmatic music, electronic music, sonic arts, soundscapes, electroacoustic music, computer music. Thus, music education and training, as a multidisciplinary subject, becomes even more difficult to learn and appreciate. Music curriculum involves aesthetics, history, sociology, psychology, science, technology together with musical theory and musical instrument learning. It is crucial for the music educators, as much as for the students, to realise that they cannot have a complete awareness of the musical world, unless they have a global knowledge of different humanitarian and scientific subjects. Electroacoustic music could become an effective teaching and learning material of different school subjects, as the students in Greek secondary education constantly grumble about not finding a connection and purpose to the different school subjects in everyday life. Students consider most teaching methods boring as they aim solely at obtaining knowledge, rather than experiencing it. Music education has also become a matter of political perspective for every government change.
Recently, the Hellenic Ministry of Education and Religion Affairs has acknowledged the important role of music in matters of communication, expression and social behaviour, in school (New School, 2011). Furthermore, music education is connected with job and career orientation and the innovative economy. University researches and scientific articles are quoted to emphasise on the intelligence, attention and concentration improvement of students via their active or passive relation to music. Additional scientific quotations explain the effect of music to stress levels, to creativity and mental clarity, to the immune system, to IQ and EQ levels. Research and bibliography has proven that music has a significant effect in student's brain and life - something that was widely acknowledged in ancient Greek times. Vast research results have proven the important role of music, either as a soundtrack, or as a creative tool for emotional expression and reflection, in increasing learning and happiness, in classrooms. The famous "Mozart Effect" (Campbell, 2001 \& 2002), the John Hopkin's study in integrating music in the classroom (Brewer, 1995) and the Active Learning Experiences (Lazarov, 1960) are characteristic examples.

To address all the above difficulties, this empirical research of different educationa programmes took place. The music education programmes of this paper, approached electroacoustic music teaching in an interdisciplinary way. The effect of electroacoustic music in improving mental, physical and emotional skills of students was examined in a rather experimental and empirical than scientific method. The empirical educational programmes were implemented in the context of emotional education at school. Emotional education in school forms the appropriate positive psychology and attitude of life (freedom of choice, good performance, a sense of acceptance from others and friendship) that allows students the self-perception, the selfimprovement and the self-development in the different growth stages. This empirical research paper has proven that students, educators, parents and generaly the school society, via electroacoustic music practices can consciously control the quality of their interpersonal relationships, manage and resolve conflicts in a mature and logical way, set and achieve high goals with substantial intrinsic motivation, self-assess without prejudice, evolve qualitatively in all areas of their lives, to succeed and be happy, shaping a healthy society that reflects the principles of their personality. Eventually, in the future, a scientific research will follow to validate the effect of the electroacoustic music methods and results of these educational programmes on enhancing interpersonal relationships in school community.

\section{CONCLUSIONS}

The integration of electroacoustic music in school community has empirically proven to achieve a great enhancement in students' attention, attitude and class atmosphere, promoted personal expression, communication and interpersonal relationships inside and outside school, has strengthened mental and physical wellbeing and prosperity. Research practices continue to take place in forming a positive psychology, a psychologically and physically healthy school environment. 
When students feel free and self-sufficient they ultimately choose for themselves the way that helps them learn and remember information more easily. When they have positive psychology and self-confidence they choose what they learn and how they process it and use it to their advantage in their lives without becoming subordinates and guinea pigs of any educational system, of any educator and his teaching or personality peculiarities, which often intend to control students and guide them to his advantage. When students have enhanced emotional skills, they understand their shortcomings and those of others (cognitive and emotional) and they work together to cover them for a better world, starting at a very young age, in a classroom, at school. The counseling services and specialists who have entered Greek school, in recent years, have been working and collaborating with students, educators, parents, the principal and the school administration in this direction, for the benefit of the whole society. The role of the school is reformed to a framework for the promotion of learning, but also, for the psycho-social development of students and their psycho-physical well-being.

In the modern school of the 21st century, the effect of electroacoustic music to human well-being and prosperity will eventually be further explored and identified within the educational systems.

\section{ACKNOWLEDGMENT}

I would like to acknowledge and thank the many people who made these educational programmes possible. First, I would like to acknowledge the support of the standing Directorate of Secondary Education, Cultural Programmes Domain of Herakleion, Crete, which offered oversight for these programmes. Secondly, I would like to acknowledge that this paper was informed by the efforts of the many fellow educators, school principals and parents who shared their data, insights, ideas, enthusiasm, and expertise with the school psychologists and programmes' supervisor, responsible for analysing and organising the outcomes of the programmes. Furthermore, I would like to thank cultural associations that lent us traditional costumes, seamstresses who made costumes for the school events on a non-profit basis, music shops, that provided PR equipment for concerts, professional musicians, who volunteered to participate as guest artist in the different school concerts, local radio and television stations that hosted and presented student work and electroacoustic compositions, professionals and scientists who kindly visited schools and gave lectures to the students, providing insight profesional data and experience. Special thanks should be granted to all the students, who, for five consecutive years, were tirelessly working, with dedication and enthusiasm, to accomplish the programmes' goals, often sacrificing enough of their personal time after school, as well as to all the parents/guardians for their support, understanding and openmindness.

\section{REFERENCES}

[1]. Boura, V. (2020). The learning effect of electroacoustic music in Secondary education. International Journal of Innovative Science and Research Technology, vol.5, issue 9.

[2]. Boura, V. (2007). The Rhetorical Method for the Critical Appraisal of Electroacoustic Structures. Journal of New Music Research, vol.36 (2), pp. 115 138.

[3]. Brewer, C. (1995). John Hopkin's Study: Integrating Music in the Classroom. http://frequencyoflearning.com/john-hopkins-studyintegrating-music-in-the-classroom/(cited in 2018)

[4]. Brewer, C. (1995). Music and Learning: Seven Ways to Use Music in the Classroom. Tequesta, Florida:LifeSounds.

[5]. Campbell, D. (2001). The Mozart Effect: Tapping the Power of Music to Heal the Body, Strengthen the Mind, and Unlock the Creative Spirit. Quill. An Imprint of Harper Collins Publishers.

[6]. DeMoss, K. \& Morris, T. (2002). How arts integration supports student learning: Students shed light on the connections. Chicago, IL: Chicago Arts Partnerships in Education (CAPE).

[7]. Lazanov, G. (1960). Accelerated Learning. https://www.learningdoorway.com/georgi-

lozanov.html (sited in 2019).

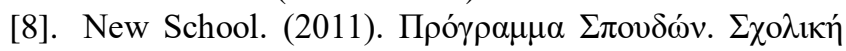

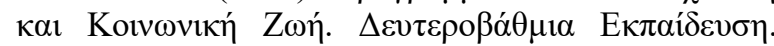

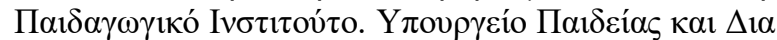

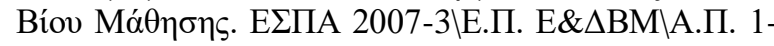
2-3. A $\theta$ íva. (Curriculum. School and Social Life. Secondary education. Pedagogical Institute. Ministry of Education and Lifelong Learning. NSRF 2007-3 OP E \& $\triangle B M \backslash$ A.П. 1-2-3. Athena).

[9]. Smalley, D. (1992). The Listening Imagination: Listening in the Electroacoustic Era in J. Paynter, R. Orton et al. (eds)-Companion to Contemporary Musical Thought vol.1, pp. 514-554. London: Routledge.

[10]. Truax, B. (1992). Electroacoustic music and the Soundscape: The Inner and Outer World in J.Paynter, R. Orton, P. Seymour, T. Howell (eds)-Companion to Contemporary Musical Thought. London: Routledge.

[11]. Wishart, T. (1994). Audible Design. York, England: Orpheus the Pantomime Ltd.

[12]. Wishart, T. (1996). On Sonic Art. The Netherlands: Harwood Academic Publishers.

\section{APPENDIX}

$>$ List of electroacoustic compositions used in the school environment

- Andrean, J. (2011). Maledetta. https://electrocd.com/en/album/5846/James_Andean/Ass emblance

- Bayle, F. (1979-80). Toupie Dans Le Ciel (New Version 2009).

https://www.youtube.com/watch?v=tyCfJbJ8ZSI 
- Berezan, D. (2014). Lightvessels. https://electrocd.com/en/album/5847/David_Berezan/Cy cle_nautique

- Berio, L. (1960). Momenti. https://www.youtube.com/watch?v=ZfZqD2iqxJ0

- Boulez, P. (1985). Dialogue de l'ombre double. https://www.youtube.com/watch?v=tRALrBqln8s

- Boura, V. (2001). Rhetoric Cue. https://sites.google.com/site/vboura/

- Cage, J. (1952) Williams Mix in Ohm: the early gurus of electronic music, Thomas Ziegler and Jason Gross.

- Cage, J. (1951). Music of Chances. https://www.youtube.com/watch?v=Y7LD1iTl-lM

- Chasalow, E. (1988) Fast Forward for Tape and Percussion in Over the Edge, New World Records, 80440-2.

- Chion, M. (2014). Les vers luisants. https://www.youtube.com/watch?v=QOZEoyS5knw

- Daoust, Y. (2005). About Time. https://electrocd.com/en/album/2430/Yves_Daoust/Voix

- Delafontaine, S. (2013). Respire marche pars va-t-en. https://electrocd.com/en/album/5917/Sophie_Delafontai ne/Accord_ouvert

- Dhomont, F. (1989) Artifices in The Human Touch, ICMC'94 International Computer Music Conference1994 Denmark.

- Dodge, C. (1980) Any Resemblance is Purely Coincidental in Computer Music Currents 11, wergo, WER 2031-2.

- Eimert, H. (1962). Epitaph for Aikichi Kuboyama, for speaker \& electronics. https://www.allmusic.com/album/herbert-eimertepitaph-f\%C3\%BCr-aikichi-kuboyama-sechs-studienmw0001438362

- Harrison, J. (2014). Espaces caches. https://electrocd.com/en/album/5678/Jonty_Harrison/Vo yages

- Henry, P. (1953). Antiphony. https://www.youtube.com/watch?v=km_MpzVtQXk

- Jean, M. (2009). Out of Joint. https://electrocd.com/en/album/5659/Monique_Jean/Tro ubles

- Justel, E. (2001). La radio, ca detend . https://electrocd.com/en/album/5926/Elsa_Justel/Yegl

- Koonce, P. (1996) Pins in Walkabout or Back, Electroacoustic Works, Mode:90

- Landy, L. (2006-07). Oh la la radio. https://electrocd.com/en/album/3482/Various_artists/Bo uquet_of_Sounds

- Lansky, P. (1978-79) "Six Fantasies on a Poem by Thomas Campion" in Fantasies and Tableaux, CRI, CD 683.

- Malt, M. (2008). Cinquieme Contemplation. https://www.youtube.com/watch?v=idLEjmi739c

- Moore, A. (2013). The Battle. https://electrocd.com/en/album/5268/Adrian_Moore/S\% C3\%A9quences_et_tropes

- Nono, L. (1988-89). La Lontananza Nostalgica Utopica Futura. https://www.youtube.com/watch?v=X-CKVm8MXxU
- Normandeau, R. (2005-06). Kuppel. https://electrocd.com/en/album/5274/Robert_Normandea $\mathrm{u} / \mathrm{D} \% \mathrm{C} 3 \% \mathrm{~B} 4 \mathrm{mes}$

- Parmegiani, B. (1975). De Natura Sonorum. https://www.youtube.com/watch?v=c_JHjUFfOs8

- Parmerud, A. (1994-95). Grains of Voices. https://electrocd.com/en/album/5840/\%C3\%85ke_Parme $\mathrm{rud} / \mathrm{Grains}$

- Reich, S. (1966). Different Trains (Europe, During the war).

https://www.youtube.com/watch?v=pZRBfRXJyak

- Risset, J.C. (1969) Mutations in Ohm: the early gurus of electronic music, Thomas Ziegler and Jason Gross.

- Roy, S. (2008). Les territoires secrets. https://electrocd.com/en/album/6045/St\%C3\%A9phane_ Roy/L_inaudible

- Schaeffer, P. (1948) Etude aux Chemins der Fer in Ohm: the early gurus of electronic music, Thomas Ziegler and Jason Gross.

- Smalley, D. (1987) Wind Chimes in Computer Music Currents 5, wergo, wer 2025-2.

- Stanovic, A. (2015). Foundry Flux. https://electrocd.com/en/album/5925/Adam_Stanovi\%C 4\%87/T\%C3\%A9n\%C3\%A9brisme

- Stockhausen, K. (1959-60) Kontakte in Ohm: the early gurus of electronic music, Thomas Ziegler and Jason Gross.

- Thome, D. (1994) Masks of Eternity in Palaces of Memory Electro-Acoustic Music Centaur, CRC2229.

- Truax, B. (2009-13). The Elements and Beyond (Chalice Well, 2009., Fire Spirits, 2010., Aeolian Voices, 2013., Earth and Steal, 2013., From the Unseen World, 2012). https://electrocd.com/en/album/5464/Barry_Truax/The_ Elements_and_Beyond

- Tudor, D. (1968) Rainforest Version 1 in Ohm: the early gurus of electronic music, Thomas Ziegler and Jason Gross.

- Varese, E. (1958) Poem Electronique in Ohm: the early gurus of electronic music, Thomas Ziegler and Jason Gross

- Vinao, A. (1989/90) Tumblers in Der Prix ars electronica 92, Prix ars electronica 92.

- Wishart, T. (1986) VOX-5 in Computer Music Currents 4, wergo, WER 2024-50.

- Xenakis, I. (1970) Hibiki-Hana-Ma in Ohm: the early gurus of electronic music, Thomas Ziegler and Jason Gross.

- Young, L.M. (1960). Composition 1960 \#7. https://www.youtube.com/watch?v=tJu4W45DyNo 